\title{
La construcción del otro en el fútbol Identidad y alteridad en los cantos de las hinchadas argentinas
}

Javier Sebastián Bundio*

Recibido

septiembre de 2017

Aceptado

marzo de 2018

\section{Resumen}

En este artículo propongo realizar un análisis de las representaciones acerca de la otredad presentes en los cantitos argentinos. Mediante ellos se escenifican representaciones acerca del "nosotros" y los "otros" construidas a partir de una lógica de la representación dicotómica y excluyente. Los hinchas no reconocen el carácter discriminatorio de los insultos porque las injurias en general forman parte de la performance y se interpretan a partir de la lógica dicotómica del aliento. De esta manera, para los hinchas, estos insultos no son graves y forman parte del "folklore del fútbol". En este sentido, mi investigación remite al estudio de las lógicas particulares del fenómeno cultural del aliento, y la articulación de estas lógicas con los procesos sociales, históricos y culturales de nuestra sociedad. Realicé un análisis discursivo de 500 cantos de cancha, entrevistas y observación participante con hinchas de 26 clubes argentinos. Expongo en primer lugar las características principales de los cantitos y el aliento para, a continuación, analizar las construcciones de la alteridad en los niveles existencial, cultural y social.

\section{The construction of other in football. Identity and otherness in the songs of Argentinian supporters}

\begin{abstract}
In this article I analyze representations about otherness present in Argentine football chants. Social representations about "us" and "others" are staged in these songs and are constructed through a dichotomous and exclusive logic of representation. Supporters do not recognize the discriminatory nature of the insults in the songs because the affronts in general are part of the performance and their interpretations are based on the dichotomous logic of "aliento", (support). Thus, for the supporters, these insults
\end{abstract}

\section{Palabras clave}

Fútbol; Identidad; Alteridad; Cantos;

Discriminación

\footnotetext{
* Doctor en Ciencias Sociales, becario postdoctoral del CONICET, Universidad de Buenos Aires, Instituto de Investigaciones Gino Germani, Ciudad Autónoma de Buenos Aires, Argentina. Correo electrónico: jbundio@gmail.com
} 
are not serious and are part of "football folklore". My research focuses on the study of the logic of the cultural phenomenon of "aliento" and its articulation with our society's social, historical and cultural processes. I perform a discursive analysis of 500 songs, interviews and participant observation with fans of 26 Argentine clubs. I discuss first the main characteristics of supporters' songs and the "aliento", and then analyze the constructions of otherness at the existential, cultural and social levels.

\section{A construção do outro no futebol. A identidade e o outro nos can- tos das torcidas argentinas}

\section{Resumo}

Palavras-chave Futebol; Identidade; Alteridade; Cantos; Discriminação
Neste artigo me proponho fazer uma análise das representações sobre as alteridades que se manifestam através dos cantos das torcidas argentinas. Neles, são encenadas as representações sobre "nós" e os "outros", sendo construídas a partir de uma lógica dicotômica e excludente de representação. Os torcedores não reconhecem a natureza discriminatória dos insultos porque as ofensas em geral fazem parte das performances e suas interpretações dependem da lógica dicotômica do "alento". Assim, para os torcedores, esses insultos não são sérios e fazem parte do "folclore do futebol". Desta forma, minha pesquisa centra-se no estudo da lógica do fenômeno cultural do "alento" e sua articulação com os processos sociais, históricos e culturais da nossa sociedade. Foi feita uma análise discursiva de 500 canções de torcidas, entrevistas e observações participantes com fãs de 26 clubes argentinos. No presente artigo, explico primeiro as principais características das canções e o "alento", para depois analisar as construções da alteridade nos níveis existencial, cultural e social.

\section{Estudios sociales del deporte: agenda y temas pendientes}

Entre los años 2009 y 2016 tuve la oportunidad de compartir con distintos grupos de hinchas una amplia gama de experiencias, tanto dentro como fuera de los estadios, que inspiraron muchas de las preguntas que fueron abordadas en mi tesis doctoral (Bundio, 2017) y que quisiera retomar en el presente artículo.

Si les preguntamos a los hinchas por los motivos que los movilizan a los estadios, su respuesta - de tan obvia que resulta para todo futbolero - se vuelve trivial: "venimos a alentar". ¿Qué quiere decir un hincha cuando refiere a su propia práctica como aliento? ¿Cuáles son los sentidos que se tejen en torno a dicha práctica? ¿Qué tipos de construcciones simbólicas se ponen en escena en el aliento? ¿Por qué, al alentar, se exhiben representaciones radicales del otro siempre negativizado e inferiorizado en diversas escalas morales? ¿Cómo interpretan los hinchas cantos que son considerados como discriminatorios desde los organismos del Estado?

En Europa fueron Armstrong (1998) y Giulianotti (1999) quienes plantearon por primera vez la necesidad de recuperar el punto de vista nativo mediante el enfoque etnográfico, y considerar a la violencia entre simpatizantes como socialmente significativa. En términos generales, la perspectiva latinoamericana recupera esta mirada. La tendencia a considerar al fútbol como un ritual comunitario, drama social o arena pública privilegia el estudio de los procesos de formación de identidades socioculturales. Esta 
inclinación por los temas culturales puede tener su origen en los trabajos pioneros de los antropólogos Roberto DaMatta (1982) y Eduardo Archetti (1985) durante la década de 1980, quienes han recuperado los aportes de investigadores de orientación antropológica para enfatizar las dimensiones simbólicas, emocionales y morales sobre las que se estructura la sociedad.

Pablo Alabarces ha continuado esta tradición e indagó sobre las narrativas de la nación mediante un análisis de los medios de comunicación y sus modos de narrar el deporte (Alabarces, 2006). Sus aportes teóricos guiaron las primeras etnografías de hinchadas, y contribuyeron a formar y a consolidar una nueva generación de investigadores que centraron su atención en las subculturas de los hinchas, con énfasis en el análisis del comportamiento simbólico, de los códigos morales y de las prácticas violentas. Los trabajos de autores como Verónica Moreira (2006) y José Garriga Zucal (2007) han tenido influencia en el resto de Latinoamérica, y contribuyeron al desarrollo de un marco teórico y metodológico útil para abordar los procesos de "barrabravización" de las hinchadas.

A pesar de la consolidación de los estudios sociales del deporte, los cantitos de fútbol no han sido objeto de estudios exhaustivos. Quizás esto se deba a su carácter banal, que lo reviste de cierta ilegitimidad académica. Incluso el término "cantitos" lo desacredita, en cierta forma, tanto dentro como fuera del campo. Esto puede deberse al desconocimiento de la riqueza simbólica de estos artefactos culturales y del intricado juego de los significados que son puestos en escena en el aliento.

También resulta llamativo que, en alrededor de 40 años de estudios sociales sobre deportes en Argentina, no existan trabajos importantes que problematicen la relación entre el fútbol y la discriminación. En términos generales, este vínculo se aborda tangencialmente en los estudios que ponen en relación identidades sociales y deporte, sobre todo en aquellos que abordan el carácter étnico de ciertas identidades futbolísticas (Gándara, 1997; Burgos y Brunet, 2000; Ferreiro, 2003; Raanan, 2012).

\section{Enfoque, métodos y preguntas}

Eduardo Archetti sostuvo que en el fútbol es posible encontrar una serie de símbolos que ayudan a las personas a pensar y categorizar sus relaciones sociales, y que esto tiene consecuencias en las maneras en que los actores sienten y perciben el mundo que los rodea. El supuesto de que por medio del fútbol es posible analizar y comprender aspectos de la realidad social implica que los actores que participan del deporte son capaces de comunicar, mediante sus prácticas, una visión del mundo (cosmovisión) y unas orientaciones valorativas (ethos). Esta distinción entre el aspecto cognitivo y el aspecto valorativo es puramente analítica y, por otro lado, en la práctica, encontramos que las representaciones del mundo social están atravesadas por valoraciones (Archetti, 1985). Cuando los sujetos seleccionan ciertos rasgos del otro para construir una representación de la alteridad, hay siempre implícito un juicio de valor que motiva esa selección (Whitley y Kite, 2010).

Aquello que los hinchas conocen como aliento constituye una performance cultural (de acuerdo con la definición de Singer, 1972) de índole agonística, que se desenvuelve mediante un duelo verbal y una práctica corporal que buscan poner en escena una imagen idealizada del propio grupo, injuriar y burlar al grupo rival e intervenir mediante la arenga en el desarrollo del partido (Bundio, 2017). Mediante esta performance, los hinchas son capaces de escenificar moralidades y, de esta manera, reafirmar identidades sociales (Archetti, 1985). 
1. La fecha de la base melódica no debe confundirse con la fecha del cantito. Así por ejemplo, "Bad Moon Rising" de Creedence, de 1985 , no fue utilizada sino

hasta 2010 por la hinchada de San Lorenzo de Almagro. El fechado de los cantos avala un análisis diacrónico, aunque limitado en la mayoría de los casos, y permite sostener que cierto léxico no era utilizado antes de la fecha de publicación de la canción original.

2. Por Buenos Aires consideré a Arsenal F. C., C. S. Dock Sud, C. A. Independiente, Racing Club, C. A. San Telmo (Avellaneda); C. Estudiantes de La Plata y C. Gimnasia y Esgrima de La Plata (La Plata); A. D. Berazategui (Berazategui),

Quilmes A. C. (Quilmes). Por CABA consideré a C. A. All Boys, A. A. Argentinos Juniors, C. A. Boca Juniors, C. Ferro Carril Oeste, C. A. Huracán, C. A. River Plate, C. A. San Lorenzo de Almagro y C. A. Vélez Sarsfield. Por Córdoba consideré a C. A. Belgrano y C. A. Talleres. Por Santa Fe consideré a C. A. Newell's Old Boys y C. A. Rosario Central (Rosario); y C. A. Colón y C. A. Unión (Santa Fe). Finalmente, consideré a Centro Juventud Antoniana (Salta), C. A. Gimnasia y Esgrima (Jujuy), y C. D. Godoy Cruz Antonio Tomba (Mendoza).
Esta puesta en escena se da mediante distintos soportes y registros de la comunicación, pero se expresan con mayor claridad en lo que los hinchas llaman "cantitos". Los cantitos son piezas contrahechas compuestas de una base melódica -tomada por lo general de la industria cultural - y una letra reformulada que se adapta a los propósitos de presentar una imagen positiva del grupo, celebrar la pertenencia, burlar o insultar al grupo rival y alentar al propio equipo (Bundio, 2013).

Las representaciones que se exhiben en el aliento se construyen mediante una lógica excluyente y polar. La selección de los rasgos de las imágenes del "nosotros" y de los "otros" está guiada por orientaciones valorativas que siguen el principio de la polarización simbólica. De esta manera, el otro es siempre representado como una alteridad radical ubicada en el polo negativo de todas las escalas morales que son relevantes para los hinchas.

Las representaciones se organizan en torno a tres núcleos del ethos: el existencial, el grupal (cultural o histórico) y el social (Archetti, 1985). A nivel existencial, el ethos se relaciona con la individualidad, el sexo o la edad, tal como lo trabajó Archetti (1985). A nivel grupal, se apoya en la construcción de sentidos vinculados a tribalismos, en este caso, la cultura del aguante (Alabarces, 2004). A nivel social, el ethos se relaciona con lo referido a la categorización del individuo como miembro de distintas categorías sociales que se constituyen a partir de líneas de fracturas históricas (Giulianotti, 2002).

La interpretación de las prácticas de aliento se da en el marco de una tensión entre una interpretación etic del aliento como práctica discriminatoria - es decir, como violencia- y una interpretación emic, que lo concibe como "folklore", es decir, como no violencia. Los hinchas no reconocen el carácter discriminatorio de los insultos basados en la pertenencia social porque las injurias en general forman parte de la performance del aliento y se interpretan a partir de la lógica dicotómica del hinchismo (Bundio, 2017). De esta manera, para los hinchas, estos insultos no son graves y forman parte del "folklore del fútbol". Esto, sumado a que el "estar alli" de la cancha constituye una situación irreflexiva, emotiva y revestida de cierto anonimato, lleva a que los insultos estén profundamente naturalizados y arraigados en el ámbito del estadio (Gándara, 1997).

Para abordar esta problemática, es necesaria una ruptura epistemológica, y plantear que toda violencia - sea esta física o verbal - es violencia con sentido, y que este sentido es contextual y situacional. Es necesario indagar los sentidos involucrados en estas prácticas para aportar a la teoría de la discriminación al explorar sus limitaciones frente a fenómenos culturales que "folklorizan" las prácticas discriminatorias.

Los cantos de cancha constituyen relatos sociales acerca de lo social que tienen la ventaja de darse en un espacio de no censura, donde las injurias explícitas están legitimadas. El aliento se escenifica en una arena pública y es atravesado por procesos de construcción de identidades de pertenencia. El análisis del contenido de los cantitos permite acceder a una serie de sentidos circulantes en la sociedad argentina en general. En este sentido, mi investigación remite al estudio de las lógicas particulares del fenómeno cultural del aliento, y la articulación de estas lógicas con los procesos sociales, históricos y culturales más amplios.

Realicé un análisis discursivo sobre un corpus de 500 cantos. Estos utilizan 126 melodías diferentes, que fueron creadas en diversos periodos históricos, en un rango de fechas que va desde 1925 (la "Marcha Radical" es la melodía más antigua de las utilizadas) a 2017 ("Despacito" de Luis Fonzi es la más reciente). ${ }^{1}$ Estos cantos corresponden a 26 hinchadas de diversas zonas geográficas. ${ }^{2}$ 
El análisis se centró en la identificación de formulaciones, adjetivaciones, predicaciones $\mathrm{y}$ atribuciones sobre los actantes del discurso. El término actante remite a una clase de actores que constituyen objetos discursivos, caracterizados por un conjunto de atributos o rasgos en común (Bal, 2001). Estos actantes fueron analizados a partir de las atribuciones (esencialmente, las adjetivaciones y predicaciones), nominaciones y la red de acciones actanciales que se establecen entre ellos.

Puesto que el aliento es un fenómeno de alcance nacional, des-territorializado y no anclado en comunidades de hinchas específicos - como el análisis puso de manifiesto-, los hinchas comparten un acervo cultural común de prácticas, categorías y sentidos más allá de su ubicación geográfica y de los particularismos regionales. Por tal motivo, la metodología empleada durante el trabajo de campo tiene paralelos con la etnografía multisituada de Marcus, ya que el objeto de estudio es producido en diferentes localidades y no necesariamente en las condiciones particulares de un grupo de sujetos (Marcus, 2001).

Buena parte de los cantitos fueron recolectados apelando a la memoria de los hinchas, mediante registros audiovisuales grabados durante las observaciones y mediante entrevistas no estructuradas. Se realizaron al menos, dos observaciones para cada hinchada, y se llevó adelante un trabajo de campo que incluyó observación participante con la hinchada de San Lorenzo de Almagro, con la que se compartieron experiencias durante dos años (2009 a 2010).

\section{El aliento y los cantitos}

El aliento establece en el espacio del estadio una relación social de antagonismo entre dos hinchadas rivales, que se disputan las representaciones acerca de sí mismas y de los otros. Al igual que sostuvo Barth (1976) para el caso de los grupos étnicos, las hinchadas se esfuerzan en conservar la definición convencional de la particular situación comunicativa en que están involucradas, para construir entre ambas la diferencia que las separa. Las hinchadas, al poner en escena la frontera grupal, provocan un efecto de uniformidad, gracias al cual las distinciones individuales se diluyen en favor de la (aparente) homogeneidad grupal, lo cual invisibiliza las diferencias individuales, a la par que se exageran aquellos rasgos que las diferencian de otras hinchadas.

El aliento constituye además un espectáculo total, porque quiebra las fronteras convencionales de la representación, al permitirles a los hinchas erigirse en actores del espectáculo (Bromberger, 2001). De esta manera, el partido de fútbol se transforma en una excusa para otro tipo de comunicación que transforma a la tribuna en un escenario performático y que tiene a la hinchada militante ${ }^{3}$ como su actor central. El aliento pone en juego un proceso de inclusión y exclusión que delimita las fronteras entre la propia hinchada y el resto de los actores.

El aliento también fragmenta el colectivo hinchada, ya que permite diferenciar entre los que cantan y los que no. De allí que cobren importancia una serie de distinciones y oposiciones al interior del propio grupo: tribuna popular-platea, hinchada-espectadores, barra-hinchas. El canto es uno de los rasgos más significativos para la autoadscripción y uno de los soportes de la identidad grupal. En efecto, cantar define a la hinchada, al erigirse en uno de los signos manifiestos por los cuales los actores exhiben su identidad. El aliento es público y performático, permite encarnar y hacer visible la abstracción de la identidad colectiva, experimentar la pertenencia mediante un acto de communitas (Turner, 1980), diluir las distinciones individuales en favor de la unidad simbolizada (Jenkins, 1996).
3. Ese grupo es el que organiza los espacios dentro y fuera del estadio - para sí mismos y para el resto de los espectadores-, confecciona y distribuye banderas (lo que en la jerga del aliento se conoce como "colgar los trapos"), crean los cantos, participan en la vida institucional del club, realizan "pintadas" (murales) en el barrio y organizan los viajes a canchas visitantes (Alabarces, 2004). 
4. En Argentina se utiliza este término peyorativo para referirse

a varones homosexuales. Sin

embargo, dentro de la cultura

del aguante, el término adquiere

sentidos vinculados a la cobardía y

a la ruptura de los códigos morales del grupo (Garriga Zucal, 2007). 5. Término vulgarmente utilizado para denominar a las trabajadoras sexuales.

6. "Negro", “cabecita negra", "villero" son todos términos con los cuales se racializa a los sectores populares más marginales y de bajos recursos en Argentina.
En términos de Bajtín, los cantitos son el género discursivo privilegiado del aliento. Este configura un campo social del lenguaje al definir un estilo verbal y un contenido. Su característica más importante es que son contrahechuras; los cantos se apropian de melodías elaboradas en la industria cultural a las que se asocia una letra de autoría propia, en cuyo proceso crean un repertorio lírico en clave intertextual e intermelódica (Bundio, 2011).

En el proceso de contrahacer una canción se da un pasaje de la industria cultural al fútbol, que luego puede trascender a otros espacios, como la política (Alabarces, 2015). Incluso, existe la posibilidad de contrahacer una contrahechura, lo que permite un pasaje de lo local a lo global mediante la apropiación que las hinchadas de otros países hacen de los cantitos argentinos. La mayoría de las bases melódicas que hoy se utilizan son tomadas de esos géneros difusos que en Argentina se conocen como rock nacional, cumbia, cuarteto, reggaetón, jingles publicitarios, música brasilera, rock y pop internacionales.

Tomando como criterio las distintas maneras de construir las imágenes del "nosotros" y de los "otros", es posible distinguir distintos tipos de cantitos. Los autoelogios celebran la propia pertenencia, al ubicar a la hinchada en los polos positivos de todas las escalas morales que son relevantes para el grupo, de tal forma que pertenecer es una forma de orgullo. Estos cantos plantean una relación romántica y pasional entre el sujeto-hincha y el equipo, la institución o la propia hinchada. Dentro de esta relación romántico-pasional, el equipo y el club se convierten en el objeto del amor y la pasión. Los insultos y las burlas son utilizados para construir una imagen de otro a partir de ciertas dimensiones comparativas que se encuadran dentro de un esquema de valores grupales, y en las que el otro es siempre inferiorizado y negativizado. Las arengas y las amenazas comparten el uso del imperativo y suelen dirigirse al propio equipo, en el caso de los primeros; a jugadores - propios y rivales-, árbitros, policías, dirigentes o la hinchada contraria, en el caso de los segundos. Las arengas constituyeron la primera forma que adquirieron los cantitos cuando aparecieron en el fútbol argentino, a principios del siglo XX. Es, además, la función primaria de los cantos, ya que a través de ellos los hinchas intentan intervenir en el desarrollo del partido. Por último, las ovaciones celebran la actuación del propio equipo o de un jugador en particular y sirven como una muestra colectiva de agradecimiento y reconocimiento.

Desde los primeros años del amateurismo hasta mediados de la década del cincuenta, los cantos se transformaron de coplas populares a contrahechuras. Se inició entonces un proceso creativo que de manera paulatina incrementaría la complejidad de estas piezas (Bundio, 2016). Este proceso se vinculó con la consolidación histórica de la hinchada militante en tanto grupo que organiza las prácticas del aliento. Durante los años setenta, se dio un pasaje de los cantos como ovaciones y arengas, a insultos y burlas. Este proceso estuvo signado por una progresiva radicalización de la relación con el otro que eclosionó con la aparición de un léxico que dio cuenta de nuevas concepciones acerca de lo masculino, el aguante, la identidad y la otredad radical (Bundio, 2016). Apareció el término "puto" "para referirse al rival, utilizado dentro de la metáfora de la violación simbólica, y el término "puta" 5 para referirse a un jugador rival. A finales de los años ochenta ya se utilizaba la figura del "negro villero"6 para referirse al hincha de Boca, y en los años noventa, esta figura devino en la del inmigrante boliviano y paraguayo. A la par que se radicalizaba la relación con el otro, el fútbol comenzó a posicionarse como identidad primaria, y el barrio-club adquirió una mayor capacidad interpeladora (Alabarces, 2000), lo que quedó ejemplificado con la aparición de los autoelogios que celebran la pertenencia a la hinchada. 


\section{Los niveles del ethos}

El aliento es una performance cultural de índole agonística que escenifica una imagen idealizada del propio grupo, a la par que elabora una imagen inferiorizada del otro. Durante la performance se da una construcción y reafirmación de las fronteras entre dos comunidades de simpatizantes definidas por criterios de adscripción. Las construcciones acerca del "nosotros" y los "otros" se construyen a partir de una lógica de la representación dicotómica, excluyente y polar. De esta manera, el otro es siempre presentado como una alteridad radical ubicada en el polo negativo de las distintas escalas valorativas organizadas en los niveles existencial, grupal y social.

En las rivalidades futbolísticas, no todas las categorías son utilizadas para representar la alteridad, sino que su presencia depende de la constitución histórica de la relación entre dos hinchadas. Es posible analizar la imagen que una hinchada pone en escena a partir de las distintas formas en que construye a los otros en tanto objetos discursivos. La Tabla 1 intenta resumir las posibles representaciones de la alteridad cruzando el eje ethos - en sus tres niveles básicos_- sobre el eje moral —en sus dos posibles valores opuestos-.

Si bien en el caso del eje vertical las fronteras parecen difusas, no ocurre otro tanto en el eje horizontal. No existe algo así como una graduación mediante la cual las representaciones del otro se van negativizando progresivamente mientras aumenta la distancia simbólica con el propio grupo. La frontera entre "nosotros" y los "otros" es clara y no admite zonas grises. Lo que puede existir es una ausencia del otro en el discurso o, en el caso de las hinchadas amigas, una inclusión del otro como un par que comparte todas las valoraciones positivas del propio grupo.

Esto no implica que a nivel interpersonal los hinchas no sean capaces de comparar socialmente su grupo con otros en una escala gradual. Ellos reconocen, en privado, que algunas hinchadas tienen más aguante que la propia, o critican a su propia hinchada por no haber alentado lo suficiente. Pero el aliento es un discurso público que presenta a las

Tabla 1. Representaciones de la alteridad. Fuente: Propia.

\begin{tabular}{|c|c|c|}
\hline & $\begin{array}{c}\text { “Nosotros" (valoración } \\
\text { positiva) }\end{array}$ & $\begin{array}{c}\text { “Ellos” (valoración } \\
\text { negativa) }\end{array}$ \\
\hline Nivel existencial & $\begin{array}{l}\text { Adultos, padres (eje edad). } \\
\text { Hombres, heterosexuales, } \\
\text { dominantes, sexuales activos, } \\
\text { reciben sexo oral (eje género/ } \\
\text { sexualidad). }\end{array}$ & $\begin{array}{l}\text { Niños, hijos (eje edad). } \\
\text { Mujeres, homosexuales, } \\
\text { travestis, dominados, sexuales } \\
\text { pasivos, practican sexo oral (eje } \\
\text { género/sexualidad). }\end{array}$ \\
\hline Nivel grupal & $\begin{array}{l}\text { Valientes, buenos peleadores } \\
\text { (eje aguante-enfrentamiento). } \\
\text { Pasionales, ganadores, fieles, } \\
\text { numerosos (eje aguante- } \\
\text { aliento). }\end{array}$ & $\begin{array}{l}\text { Cobardes, malos peleadores } \\
\text { (eje aguante-enfrentamiento). } \\
\text { Apáticos, infieles, poco } \\
\text { numerosos (eje aguante- } \\
\text { aliento). }\end{array}$ \\
\hline Nivel social & $\begin{array}{l}\text { Blancos (eje etnia). } \\
\text { Cristianos (eje religión). } \\
\text { Peronistas, democráticos (eje } \\
\text { política/ideología). } \\
\text { Clase media, trabajadores } \\
\text { integrados (eje clase). } \\
\text { Barrio, ciudad, provincia } \\
\text { propio/a; argentinos (eje } \\
\text { territorio/Nación). }\end{array}$ & $\begin{array}{l}\text { Mestizos, indígenas (eje etnia). } \\
\text { Judíos (eje religión). } \\
\text { Antiperonistas, autoritarios (eje } \\
\text { política/ideología). } \\
\text { Marginales, ricos, trabajadores } \\
\text { precarios (eje clase). } \\
\text { Barrio, ciudad, provincia } \\
\text { ajeno/a; extranjeros (eje } \\
\text { territorio/Nación). }\end{array}$ \\
\hline
\end{tabular}


7. Se conoce como macho al varón heterosexual que se ajusta a modelos ideales de hombría definidos por la cultura del aguante (Garriga Zucal, 2007). relaciones entre las categorías de cada nivel como excluyentes y polares. La distinción entre "nosotros" y los "otros" no parte de distinciones fácticas sino de diferenciaciones construidas a partir de los rasgos que el grupo considera significativos (Barth, 1976). La lógica de la representación en el aliento lleva a la exageración de estas diferencias significativas, de tal manera que el otro se presenta como una alteridad radical.

A pesar de su esquematismo, resulta una tabla conceptual útil para analizar las distintas formas en que una hinchada construye simbólicamente a su rival. Es, asimismo, una herramienta útil para comparar prácticas de aliento en distintos países o en distintas épocas. Por ejemplo, en el caso del clásico irlandés, el nivel religioso, territorial e ideológico cobra un sentido importante en la construcción de un Celtic de orientación celta y católica, opuesto a un Ranger de orientación británica y protestante. En cambio, la homofobia - como han notado varios autores- es un tema recurrente en los estadios de todo el mundo (Dunning, Murphy y Williams, 1986).

No todas las categorías tienen presencia en los cantos, sino que esta depende de la constitución histórica de la relación entre dos hinchadas. Así, dos hinchadas sin una rivalidad fuerte basarán sus construcciones simbólicas en el eje existencial y grupal; mientras que dos hinchadas con una rivalidad fuerte y de barrios cercanos tenderán a construir sus representaciones sobre el eje social. Resulta claro que a finales del siglo XX se incrementó la violencia simbólica de los cantos, con lo cual se radicalizaron las relaciones entre "nosotros" y "ellos". Las construcciones de la otredad viraron desde los ejes etarios, sexuales y territoriales hacia los ejes étnicos-clasistas y el nivel grupal (Bundio, 2017).

\section{Moralidades masculinas}

En el aliento, los hinchas participan de la construcción de un orden y un mundo masculino, que se organiza de manera polar a partir de la dicotomía hombres-no hombres (Archetti, 1985). En este mundo varonil, también las mujeres pueden ser enunciadoras, pero los enunciados son del orden de lo masculino. El proceso de tribalización facilita la incorporación de las mujeres a las hinchadas, pero no les brinda la posibilidad de construcción de un espacio autónomo (Alabarces, 2000). Los cantos ponen en relación un conjunto de ideas, imágenes, sentimientos, valores y estereotipos propios de un mundo de hombres.

El ethos masculino afirma la virilidad en torno a los ejes contrapuestos de homosexual y niño. El aliento reafirma las identidades varoniles exagerando las diferencias padrehijo, "macho"7-homosexual, pero dejando afuera el par oposicional hombre-mujer (Binello y otros, 2000). La principal referencia a la mujer en los cantos es la categoría de "puta". En el campo metafórico del aliento, este insulto asigna a otro hombre la posición del dominado y el humillado.

En este punto, existe una equivalencia entre las figuras de la mujer y el homosexual, ya que la inferiorización del otro no pasa tanto por el género, sino por asumir o adjudicarle un rol pasivo en el acto sexual. De esta forma, la presencia de las mujeres en los estadios es negada en el proceso de construcción de un orden simbólico enteramente masculino. Esto puede deberse a que las mujeres no desafían ni cuestionan la masculinidad al no amenazar la heterosexualidad del varón (Binello y otros, 2000).

La categoría de los "no-hombres" incluye al menos dos tipos de negaciones de la masculinidad: los proyectos de hombres - los no adultos - y los homosexuales — "falsos hombres"- Podemos encontrar ambas categorías en los cantos de todas las hinchadas. Si bien la categoría de hijo puede ser pasajera, la categoría de "puto" se concibe de 
manera esencializada y atemporal. El uso de la categoría "hijo" depende de la existencia de un palmarés favorable a uno de los clubes en relación con su clásico deportivo. Mientras que la categoría "puto" puede usarse indiscriminadamente.

La relación padre-hijo y adulto-niño reafirma las estructuras jerárquicas del universo masculino. Esta concepción involucra nociones de autonomía, independencia y capacidad de ejercer libremente la voluntad (Archetti, 1985). La metáfora padre-hijo remite a una cuestión de poder y diferencia de estatus; el hijo está sometido a la voluntad del padre, quien le niega la victoria.

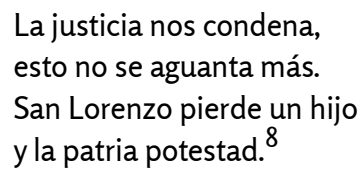

En el aliento encontramos una expresión autoritaria de la sexualidad que convierte al otro en una "anomalía" del género. La sexualidad del victorioso se ejerce a través de la violación y humillación del otro (Archetti, 1985). Detrás de esta metáfora existe una cuestión de poder, ya que la negación de la masculinidad del otro se da mediante un acto de dominación. La condición de homosexual no es asumida, sino impuesta por la fuerza mediante el sometimiento. Se representa al otro como un ser que hace cosas en contra de su voluntad, como un ser sometido y obligado por el hombre más fuerte a someterse.

\section{Despacito, despacito, despacito,} les rompimos el culito. ${ }^{9}$

La categoría de "puto" se asocia además a concepciones acerca de la cobardía y la ruptura de los códigos de conducta de la cultura del aguante. Esto supone un vínculo entre el nivel existencial y el nivel grupal de las representaciones de la otredad. Los verdaderos hombres son aquellos que demuestran tener aguante y atenerse a códigos grupales de conducta. Aquellos que no lo hacen quedan por fuera del mundo masculino.

No somos como esos putos de Estudiantes

que corrió Gimnasia por la Diagonal. ${ }^{10}$

\section{La cultura del aguante}

Cada espacio moral define lo aceptable y lo inaceptable según los valores del grupo, y estas construcciones son históricas y dinámicas (Fassin y Bourdelais, 2005). Podemos considerar a las hinchadas como comunidades morales (Bayley, 1971) que comparten un conjunto de valores que las distinguen y diferencian. Son estas definiciones morales las que delimitan las fronteras de la comunidad, al señalar los límites de la grupalidad y permitir los procesos de identificación y la construcción de sentidos de pertenencia.

Para las hinchadas argentinas existen dos grandes principios que organizan no sólo las representaciones, sino también las prácticas grupales y la moralidad del grupo. Me refiero a lo que en términos nativos se conoce como aliento y como aguante. Juan Sodo propone distinguir al "aguante-aliento" del "aguante-enfrentamiento", pero señala que son categorías fuertemente vinculadas (Sodo, 2011). El aguante-enfrentamiento es el que posee la "barra", 11 se prueba en el enfrentamiento físico y se mide en cantidad de heridas, trapos robados o anécdotas. Por otro lado, el aguante también se prueba mediante la resistencia estoica y de carácter festivo, es decir, mediante el aguante-aliento.
8. Cantito de la hinchada de San Lorenzo de Almagro.
9. Cantito compartido por casi todas las hinchadas y que se canta luego de una victoria apabullante.

10. Cantito de la hinchada de Gimnasia y Esgrima de La Plata.

11. "Barra brava" o "barra" es un grupo dentro de la hinchada militante que, generalmente, ejerce un mayor nivel de violencia en sus enfrentamientos y que mantiene una relación económica o instrumental con la dirigencia, o con parte de la dirigencia, de un club (Alabarces, 2004). 
12. Cantito compartido por varias hinchadas y que se le cantaba en los años noventa a Boca Juniors.
13. Cantito de la hinchada de San Lorenzo de Almagro dirigido a la hinchada de Independiente de Avellaneda.
Originariamente, aguante hacía referencia a "hacerle el aguante a", o sea, alentar al equipo pese a la adversidad. Durante los años ochenta, el término aguante se cargó de significados asociados con el enfrentamiento cuerpo a cuerpo, y se constituyó así en un principio organizador de la vida grupal mediante el cual se definía un modelo ideal de hombría (Alabarces, 2004). Alentar implica ser pasional y expresar estos sentimientos, comparte con la categoría de aguante la necesidad de "poner el cuerpo" pero no ya en prácticas violentas, sino para ejercer una violencia simbólica sobre el otro y para celebrar la propia pertenencia mediante la "fiesta" y el "carnaval".

El universo de las hinchadas está atravesado no sólo por una lógica trágica (que podemos asociar al aguante), sino por una instancia cómica y festiva (asociada al aliento). Es la combinación de ambas facetas la que nos permite identificar rasgos asociados comúnmente con el juego, entendido este como un espacio de creación, libertad y espontaneidad (Moreira y Bundio, 2014). En este contexto, el uso de este doble registro - lo trágico y lo cómico simultáneamente- produce un efecto jocoso y divertido entre los participantes. La dimensión cómica y la dimensión trágica se enlazan en la entonación de los cantos que exaltan la muerte (pasada o futura) del rival.

$$
\begin{aligned}
& \text { Saturnino, Saturnino, } \\
& \text { Saturnino se murió. } \\
& \text { Le tiraron con un caño } \\
& \text { y el boludo cabeceó. }{ }^{12}
\end{aligned}
$$

Lo opuesto al aliento es la amargura, es decir, la ausencia de pasión, que evidencia que el contrato romántico-pasional del hincha con su club es simplemente una fachada y no una expresión real de la fidelidad y de los propios sentimientos. El sentimiento de un hincha por su club es siempre representado como esencialista, atemporal y excluyente. Los polos opuestos del eje aliento-amargura se construyen a partir de las diferenciaciones sobre lo que los hinchas consideran "la pasión".

Rojo de Avellaneda,

Llená una cancha antes de hacer una nueva.

Esa tribuna es una postal

Independiente la Amargura Nacional.

Si perdieras un estadio,

Si te fueras a la B

Al Glorioso Independiente

Nadie lo iría a ver.

Fuistes el Rey de Copas

Pero ese verso hace unos años terminó.

Ahora te queda volver a ver

Esos videos que son del 73.

Yo no necesito copas, yo vivo de mi pasión,

Esa que sólo entiende el que es hincha del Ciclón.

Somos tan diferentes,

Vos con tus copas yo me quedo con mi gente.

Esa que alienta en cualquier lugar

La que nos hace ser un grande de verdad.

Yo no necesito copas, ni tampoco ser campeón,

La grandeza azulgrana se forjó desde el tablón. ${ }^{13}$

En el caso del aguante-enfrentamiento, la argumentación de los hinchas se puede resumir en "a mayor riesgo físico, mayor aguante"; es decir, cuando un hincha pone en juego su propio cuerpo - y su propia vida - pone en escena que "se la aguanta de verdad". Lo opuesto a aguantar ya no es ser amargo, sino ser un cobarde - es decir, 
un "puto", un "no-hombre"-. Lo que en términos nativos se conoce como "correr", el abandono del campo de batalla, implica dejar de poner en riesgo la propia vida.

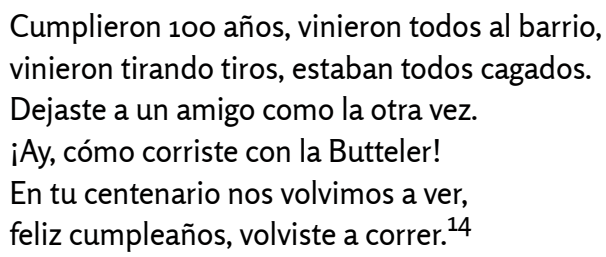

La muerte del otro es celebrada como una muestra de aguante de la propia hinchada y de falta de "huevos"15 del rival, lo que coloca a este en la categoría de "no-hombre" o "puto": "Esos putos que corrieron se llevaron a un amigo en el cajón". Quien no aguanta también busca protección policial, de ahí que se asocie la falta de aguante con ser policía o "vigilante”. Quien no se la aguante físicamente — es decir "mano a mano"utiliza armas de fuego, algo que para los hinchas es moralmente condenable: "siempre corriendo siempre tirando tiros dejaste a un amigo porque sos un cagón”. ${ }^{16}$

\section{Categorías etnocéntricas}

El nivel social del ethos nuclea una serie de representaciones sobre la alteridad que se organizan en torno a un núcleo de identidad étnico-clasista. ${ }^{17}$ Los cantos ponen en escena configuraciones de sentido gestadas en la época colonial y que permanecieron en los códigos culturales incorporados a los mecanismos de constitución de hegemonías a lo largo de la historia de Argentina (Margulis y Belvedere, 1999). El aliento escenifica una serie de categorías, imágenes, sentimientos y moralidades que parten del supuesto de la superioridad racial del hombre blanco en relación con el mestizo. La presencia simbólica de esta figura tiene fuerte influencia en nuestra cultura y nuestras relaciones sociales; interviene en los procesos de construcción social de sentido, en la evaluación social y en las formas de apreciación y gozo de modelos estéticos.

La presencia de estas categorías en el aliento sería impensada sin la existencia de estereotipos que ligan a una comunidad de hinchas con una de inmigrantes. Los insultos y las burlas que contienen los cantos tampoco serían efectivos sin la presencia generalizada y naturalizada de fuertes prejuicios negativos sobre estas comunidades. Estas representaciones surgen en los años ochenta, cuando la otredad pasa a ser el otro lejano - el extranjero latinoamericano - y el otro cercano - el mestizo pobre-. El aliento construye al otro al identificarlo y hacerlo visible mediante el lenguaje.

Los cantos ponen en escena imágenes de una otredad pobre, marginada social y territorialmente, sobre la que pesa un imaginario que le atribuye una serie de características negativas. Las representaciones sobre el otro mestizo en los cantos de cancha contribuyen al mantenimiento de una frontera étnica que, paradójicamente, parece no existir; ya que el imaginario colectivo está anclado en el mito fundacional de la supuesta unidad étnica europea argentina.

La categoría "barrio" se recubre de fuerte capacidad interpeladora, cargada de significaciones esencialistas. Ese micro-territorio, o "guetto imaginado" (Bundio, 2017), se concibe como reserva moral y reserva de lo local frente a las tensiones desterritorializadoras (Alabarces, 2000). Es en el barrio donde las identidades nacionales son reafirmadas frente al otro inmigrante, que se imagina en barrios futbolísticamente rivales. Estas identidades locales se sustentan en representaciones de la otredad que se construyen sobre la base de ejes étnicos y de clase, ya que los hinchas rivales son imaginados como provenientes de guetos donde reside la otredad inmigrante y mestiza.
14. Cantito de la hinchada de San Lorenzo de Almagro dirigido a la hinchada de Huracán de Parque Patricios. 15. Testículos. "Tener huevos" implica poseer hombría y valentía.

16. Extracto de un cantito de la hinchada de San Lorenzo de Almagro dirigido a Huracán de Parque Patricios.

17. Me centré en el análisis de las representaciones sobre el "otro mestizo", dejando de lado la construcción del "otro semita”, ampliamente investigado por Raanan (Raanan, 2012). 
18. Cantito de la hinchada de Gimnasia y Esgrima de Jujuy, dirigido a la hinchada de Juventud Antoniana de Salta.

19. Cantito de la hinchada de San Lorenzo de Almagro, dirigido a la hinchada de Boca Juniors.

20. Otro cantito de San Lorenzo dirigido a la hinchada de Boca Juniors.
Las fronteras simbólicas entre las poblaciones de inmigrantes latinoamericanos y migrantes internos son difusas. La construcción del otro como extranjero y mestizo excede toda explicación sociohistórica y pierde cualquier anclaje con la realidad social. En una misma categoría se incluye al pobre, al migrante interno y al inmigrante latinoamericano, de tal manera que no existe una distinción clara entre estas categorías.

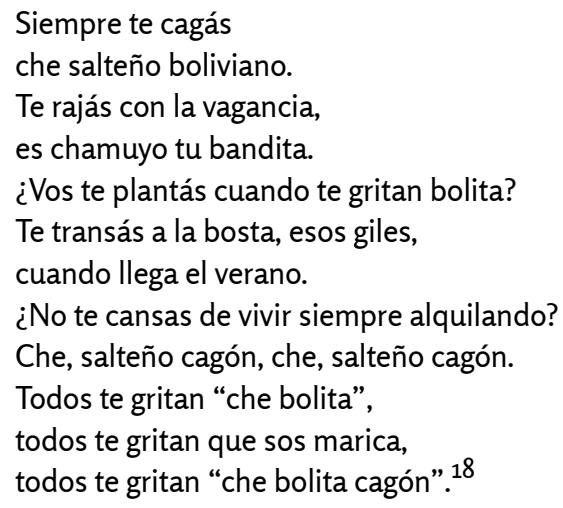

La oposición entre un enunciador que se imagina europeo y blanco y un sujeto representado como latinoamericano y mestizo está atravesada por todo un conjunto de evaluaciones y valoraciones que conforman un cuadro en el que se manifiesta claramente que las costumbres, los modales, la vestimenta, el lenguaje, la higiene, las comidas, los pasatiempos y hasta los gustos musicales están asociados a ciertos tipos de cuerpos y clases sociales (Bundio, 2017). Consumos como la cumbia villera, alimentos y bebidas de segundas marcas - en pocas palabras, los consumos populares - son pensados como vulgares.

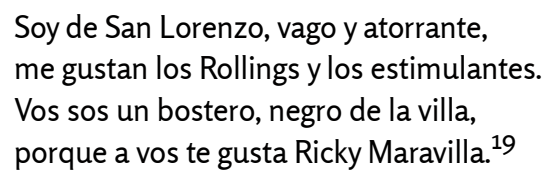

Las nociones sobre la higiene señalan que lo sucio está siempre por fuera de las fronteras del propio grupo, como algo ajeno, vulgar y escatológico. La frontera simbólica entre las hinchadas es también un límite entre lo limpio y lo sucio, donde la suciedad es asociada a otredades que son construidas como impuras. La categoría de suciedad aparece en adjetivaciones, en las expresiones escatológicas y mediante la construcción de un territorio sucio, pero a la vez próximo.

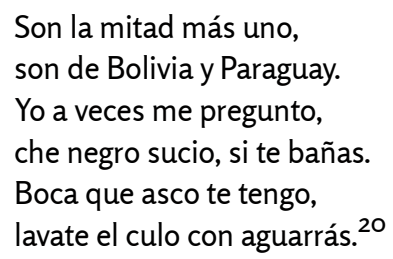

Lo interesante de este proceso de construcción de otredades a partir de argumentos socioeconómicos, políticos y geográficos es que se recurre la figura del inmigrante para representar al otro como un sujeto inferior en lo social, económico y cultural. Las villas son interpretadas desde una ideología etnocéntrica, que las concibe como espacios de marginalidad.

Desde el punto de vista del enunciador, la propia identidad se construye tanto respecto del nivel inferior ("villero") como del nivel superior ("cheto") de la estructura de 
clases. De forma tal que la dicotomía que opera detrás de estas imágenes no es la de pobre-rico, sino la de "barrial"-"cheto" y "barrial"-"villero". ${ }^{21}$

\author{
Hay una banda en la Entre Ríos \\ todos amargos todos pechos fríos. \\ Una va al shopping, la otra vende frutas \\ van a la Lerma, siempre con la yuta. \\ Sos cagón, sos cagón, Cuervo y Albo sos cagón. ${ }^{22}$
}

\section{Aliento y discriminación: reflexiones finales}

Por intermedio de la metáfora se asocian categorías sociales a grupos de hinchas. De esta manera se enfatizan ciertos rasgos, se suprimen otros y se organizan los distintos aspectos del sujeto destinatario del mensaje. Esta organización de rasgos sigue el principio de la polarización simbólica, una lógica de la representación del aliento que es excluyente y dicotómica. Pero ¿qué implicancias tienen estas construcciones para los sujetos? ¿Qué sentidos les asignan los hinchas a estas metáforas?

Resulta de utilidad la distinción que realiza Ducrot entre autores, enunciadores y locutores de un discurso (Ducrot, 1984). Frente al efecto homogeneizador de los cantos que instauran un enunciador, debemos preguntarnos sobre la subjetividad de los locutores individuales y las maneras en que se apropian de los sentidos del mensaje, lo resisten o negocian sus significados. En este punto, podemos encontrar una diversidad de miradas, desde la adhesión al sentido literal del mensaje hasta el rechazo rotundo, pasando por posiciones que mitigan la gravedad de estos cantos, que indican que deben comprenderse en el marco interpretativo configurado por el aliento, en el que esas prácticas adquieren nuevos sentidos y legitimidad.

Los hinchas participan del aliento con diferentes niveles de involucramiento. La musicalización del aliento entrelaza en la tribuna un conjunto de relaciones sociales donde radica la verdadera importancia y significancia simbólica de lo que se canta (Collinson, 2009). El aliento provee a los hinchas de una afirmación de la comunidad a través de un acto de exploración y uno de celebración.

Las burlas e injurias del aliento mantienen las dicotomías y las diferencias. El aliento constituye una situación comunicativa de carácter lúdico en la que los mensajes que se emiten buscan deteriorar o destruir la imagen del otro, al igual que otras actuaciones culturales (Goffman, 1986). Lo que los interactuantes buscan es señalar las diferencias mediante actos descorteses que implican una búsqueda activa del conflicto, al generar un desequilibrio entre las imágenes sociales de los distintos interlocutores (Fuentes Rodríguez, 2008).

Los hinchas agredidos no se sienten para nada ofendidos, sino que lo toman como parte del juego que rodea a un partido de fútbol, y tienen a su vez la ocasión de responder a la ofensa. Incluso, el motivo principal de la comunicación no es necesariamente la intención de dañar la imagen del otro, sino que el fin parece ser la celebración de la propia pertenencia, en concordancia con lo observado por Collinson (2009).

Si asumimos que la violencia no existe sin cultura, sino que es resultado de procesos socioculturales (Sanmartín, 2009), entonces debemos asumir que los hinchas no conceptualizan estas ofensas como violencia. La convivencia entre uno y otro grupo de hinchas no se alcanza por la búsqueda del acuerdo, sino por el respeto a las reglas del aliento, que construye un campo metafórico - contrato de lectura (Verón, 1985) o pacto ficcional (Searle, 1986) - en el que la amenaza a la imagen del otro es permanente.
21. Queda pendiente la pregunta sobre la relación entre el sujeto enunciador (la hinchada) y el sujeto locutor (los hinchas individuales). Resulta innegable que los sectores populares que son estigmatizados adhieren a diversos clubes, entre ellos, aquellos que los estigmatizan.

22. Cantito de la hinchada de Juventud Antoniana de Salta dirigido a sus dos rivales salteños, Gimnasia y Tiro y Central Norte. 
Existe una distancia entre lo que los hinchas dicen - sentido literal del mensaje- y lo que quieren decir - intención comunicativa u orientación-. Las injurias significan en el momento en que se usan, ya que se relacionan de forma privilegiada con el acto de enunciación (Angenot, 2010). Creo que esta postura es mucho más adecuada que la pragmática, que consideraría que, pese a no haber tematización de la afrenta, la injuria existe ya que está contenida en el nivel oracional. En ese intercambio recíproco entre pares, la violencia simbólica que suponen estos mensajes se diluye al ser estos interpretados desde claves culturales que ven en los cantos ofensivos una práctica lúdica, que transgrede límites culturales y permite representar lo que en otros ámbitos es tabú.

El anonimato y el carácter colectivo de los cantos legitiman decir aquello que no está permitido decir en otros espacios sociales, y la tribuna se convierte entonces en un espacio de la "no censura". Al igual que el carnaval, el aliento permite decir lo no decible, porque ha constituido un espacio carnavalesco, que tiene como epicentro la tribuna popular.

Los cantos son expresiones cómicas y comparten con los chistes el carácter de ser discursos no serios, que construyen un espacio para la expresión legítima de estigmas sociales, prejuicios y estereotipos. Lo cómico realiza en forma completa toda la carga de violencia que el discurso no serio puede canalizar (Escarpit, 1972). La distancia afectiva determina una separación entre los que ríen y los que hacen reír, y funciona como una práctica de exclusión que sirve para distanciar y para dominar. En los cantitos, la distancia afectiva es doble, con el hincha rival y con el otro (ya sea el homosexual, el inmigrante, el mestizo o cualquier categoría social relevante); es precisamente esa distancia lo que permite la risa.

Preguntarse acerca de la relación entre fútbol y sociedad implica reflexionar sobre las distintas maneras en que el campo futbolístico es permeable a los estereotipos y prejuicios circulantes en la sociedad. Es innegable que el fútbol no constituye un campo autónomo con respecto a la sociedad, sino que elabora sus propios sentidos y relatos al recuperar, reinterpretar y revalorizar significados sociales. También se transita el camino inverso, símbolos y categorías propias del fútbol son utilizados para dar un sentido al orden social.

Entre estereotipos, prejuicios y discriminaciones existe una relación compleja y no causal, esta relación es innegable. Podemos pensar que aquello que se expresa deja una huella en la subjetividad que puede ser reactivada en determinados momentos de tensión social. Las representaciones sobre el otro no son sólo categorizaciones de personas sino también valoraciones, y el fútbol contribuye a reafirmarlas y a legitimar agresiones físicas posteriores.

No debe considerarse que esté avalando la idea de que el fútbol es un reflejo de la sociedad; todo lo contrario. Aquello que se pone en escena en el aliento constituye en parte una expresión literal de las creencias de muchos hinchas, pero por otro lado, constituye la forma particular que han adquirido las burlas e injurias tradicionales en el fútbol, que han seguido un camino hacia lo extremo y radical. Es por este último proceso que muchas manifestaciones que, en otros ámbitos, podrían considerarse discriminatorias no son interpretadas por los hinchas de esa manera, ya que constituyen para ellos parte del repertorio tradicional del aliento.

La extensión, naturalización y legitimidad de estas prácticas debe llevarnos a una reflexión sobre la identificación de los hinchas a una formación discursiva, ya que la adhesión al canto puede llegar a movilizar fuerzas sociales. Incluso aquellos hinchas 
que mitigan la gravedad de ciertas ofensas - basadas en la pertenencia social- reconocen los prejuicios negativos que se encuentran velados o son negados socialmente. Es necesario alejarse de una visión esquemática del canto discriminatorio que lo presente, ya sea como mero reflejo de la sociedad, ya sea como simple campo metafórico sin implicancias con lo social, y ver las complejas maneras en que estos enunciados movilizan y legitiman acciones discriminatorias en otras esferas sociales.

Esto explica, en parte, por qué el Estado ha sido eficaz en disminuir las prácticas discriminatorias en otros espacios sociales pero no en el fútbol, que continúa siendo un lugar donde se admite una violencia simbólica extrema (racismo, homofobia, xenofobia, sexismo y etarismo, entre muchos otros "ismos" posibles). Debemos considerar a la violencia simbólica como una condición más que posibilita las prácticas violentas en los estadios de fútbol.

Muchos hinchas se niegan rotundamente a participar de este tipo de prácticas de aliento, y se sienten particularmente ofendidos y avergonzados. Es decir, si bien el aliento como performance cultural reafirma identidades sociales y escenifica moralidades, lo hace en un campo signado por la disputa de sentidos por parte de distintos actores. La cultura, en tanto dimensión simbólica constituyente de los fenómenos sociales, no sólo legitima las desigualdades, sino que también las construye y de-construye. Quizás la tarea más importante respecto de este punto sea de-construir el campo metafórico que sirve de marco interpretativo a los cantos ofensivos e intentar recuperar las metáforas futbolísticas como parte de un juego lúdico responsable. 


\section{Q Bibliografía}

"ALABARCES, Pablo. 200o. “'Aguante' y represión. Fútbol, violencia y política en la Argentina". En: P. Alabarces (Ed.). Peligro de Gol. Estudios sobre deporte y sociedad en América Latina. Buenos Aires: CLACSO. pp. 211-230.

»ALABARCES, Pablo. 2004. Crónicas del aguante. Fútbol, violencia y política. Buenos Aires: Capital Intelectual.

» ALABARCES, Pablo. 2015. "Fútbol, música y narcisismo: algunas conjeturas sobre 'Brasil, decime qué se siente'”. El Oído Pensante, 3(1): 1-19.

» ANGENOT, Marc. 2010. El discurso social. Buenos Aires: Siglo XXI.

" ARCHETTI, Eduardo. 1985. "Fútbol y ethos". Monografías e Informes de Investigación, 1(7): 71-109.

" ARMSTRONG, Gary. 1998. Football Hooligans. Knowing the Score. Londres: Berg.

» BAL, Mieke. 2001. Teoría de la narrativa. Madrid: Cátedra.

» BARTH, Fredrik. 1976. “Introducción”. En: F. Barth (Ed.). Los grupos étnicos y sus fronteras. México: Fondo de Cultura Económica. pp. 9-49.

» BAYLEY, Frederick. 1971. Gifts and Poison: the politics of reputation. Oxford: Basil Blackwell.

"BINELLO, Gabriela, CONDE, Mariana, MARTíNEZ, Analía y RODRíGUEZ, María Graciela. 200o. “Mujeres y fútbol: ¿territorio conquistado o a conquistar?". En: P. Alabarces (Ed.). Peligro de Gol. Estudios sobre deporte y sociedad en América Latina. Buenos Aires: CLACSO. pp. 33-74.

" BROMBERGER, Christian. 2001. Le match de football. Ethnologie d'une passion partisane à Marseille, Naples et Turin. París: Èditions de la Maison des sciences de l'homme.

" BUNDIO, Javier Sebastián. 2011. Duelo en las gradas: la ideología de grupo desplegada en el canto de una hinchada de fútbol. Saarbrücken: Editorial Académica Española.

» BUNDIO, Javier Sebastián. 2013. “El hinchismo como ideología radical”. Revista Kula. Antropólogos del Atlántico Sur, 1(8): 60-68.

" BUNDIO, Javier Sebastián. 2014. “Redes de rivalidades y alianzas en el fútbol argentino”. Revista del Museo de Antropología, 7(2): 371-378.

" BUNDIO, Javier Sebastián. 2016. "Un análisis del contenido y la melodía de los cantos de cancha desde sus orígenes hasta las tendencias actuales". En: A. Levoratti y V. Moreira (Eds.). Deporte, cultura y sociedad. Estudios socio-antropológicos en Argentina. Buenos Aires: Godot. pp. 271-294.

"BUNDIO, Javier Sebastián. 2017. Hinchadas y otredades radicales. Un estudio antropológico de los cantos en los estadios de fútbol argentinos. Tesis de doctorado, Universidad de Buenos Aires.

» BURGOS, Ramón y BRUNET, Marcelo. 2000. "Un análisis de los cantos de los hinchas de Gimnasia y Esgrima de Jujuy”. Lecturas, Educación Física y Deportes, 1(26): 1-4.

" COLLINSON, lan. 2009. "Singing Songs, Making Places, Creating Selves: Football Songs \& Fan Identity at Sidney FC". Transforming Cultures ejournal, 4(1): 15-27. 
» DA MATTA, Roberto. 1982. “Esporte na sociedade: em ensaio sobre o futebol brasileiro”. En DaMatta, R. (Ed.). Universo do Futebol: esporte e sociedade brasileira. Río de Janeiro: Pinakotheke. pp. 19-42.

»DUCROT, Oswald. 1984. El decir y lo dicho: polifonía de la enunciación. Barcelona: Paidós.

»DUNNING, Eric, MURPHY, Patrick y WILLIAMS, John. 1986. “Spectator Violence at Football Matches: Towards a Sociological Explanation”. The British Journal of Sociology, 37(2): 221-224.

»ESCARPIT, Robert. 1972. El humor. Buenos Aires: Eudeba.

" FASSIN, Didier y BOURDELAIS, Patrice. 2005. "Introduction: les frontières de l'espace moral”. En: D. Dassin y P. Bourdelais (Eds.). Les constructions de l'intolérable. Études d'anthropologie et d'histoire sur les frontières de l'espace moral. París: La Découverte Collection "Researches". pp. 7-15.

» FERREIRO, Juan Pablo. 2003. “'Ni la muerte nos va a separar, desde el cielo te voy a alentar': apuntes sobre identidad y fútbol en Jujuy”. En: P. Alabarces (Ed.). Futbologías. Fútbol, identidad y violencia en América Latina. Buenos Aires: CLACSO. pp. 57-74.

» FUENTES RORÍGUEZ, Catalina. 2008. (Des)cortesía, agresividad y violencia verbal en la sociedad actual. Sevilla: Servicio de Publicaciones de la Universidad de Sevilla.

» GÁNDARA, Lelia Mabel. 1997. "Las voces del fútbol. Análisis del discurso y cantos de cancha”. Literatura Lingüística, 10(1): 43-66.

» GARRIGA ZUCAL, José. 2007. Haciendo amigos a las piñas: violencia y redes sociales de una hinchada de fútbol. Buenos Aires: Prometeo.

» GIULIANOTTI, Richard. 1999. Football. A Sociology of the Global Game. Cambridge: Polity Press.

» GIULIANOTTI, Richard. (2002). "Supporters, Followers, Fans, and Flâneurs”. Journal of Sport and Social, 26(1): 25-46.

» GOFFMAN, Erving. 1986. Frame Analysis. An Essay on the Organization of Experience. Boston: Northeastern University Press.

» JENKINS, Richard. 1996. Social Identity. Londres: Routledge.

» MARGULIS, Mario y BELVEDERE, Carlos. 1999. “La ‘racialización’ de las relaciones de clase en Buenos Aires: genealogía de la discriminación”. En: M. Margulis y M. Urresti (Eds.). La segregación negada: cultura y discriminación social. Buenos Aires: Biblos. pp. 79-122.

» MOREIRA, Verónica. 2006. “Trofeos de guerra y hombres de honor”. En : P. Alabarces (Ed.). Hinchadas. Buenos Aires: Prometeo. pp. 75-89.

» MOREIRA, Verónica y BUNDIO, Javier Sebastián. 2014. “Rivalidad, juego y disputa: prácticas de aliento entre hinchas de fútbol en Argentina”. Lúdicamente, 3(6): 1-19.

" RAANAN, Rein. 2012. Los bohemios de Villa Crespo. Judíos y fútbol en la Argentina. Buenos Aires: Sudamericana.

» SANMARTíN, José. 2009. La violencia y sus claves. Barcelona: Editorial Ariel.

»SEARLE, John. 1986. Actos de habla. Ensayo de filosofía del lenguaje. Barcelona: Planeta Agostini.

» SINGER, Milton. 1972. When a Great Tradition Modernizes. Nueva York: Praeger. 
" SODO, Juan Manuel. 2011. Prácticas de sociabilidad en un grupo de hinchas del fútbol argentino y sus vinculaciones con la producción de ambientes de violencia en torno del espectáculo futbolístico. Tesis de doctorado, Universidad Nacional de Rosario.

" TURNER, Victor. 1980. La selva de los símbolos. Madrid: Siglo XXI.

»VERÓN, Eliseo. 1985. Les Medias: Experiences, recherches actuelles, aplications. París: IREP.

»WHITLEY, Bernard y KITE, Mary. 2010. The Psychology of Prejudice and Discrimination. Belmont: Wadsworth. 